\title{
Bela, recatada e do lar: uma análise discursiva das posições-sujeito da mulher na revista Veja
}

\author{
Beautiful, demure, and housewife: a discursive analysis of \\ the subject-positions of women in Veja magazine
}

\author{
Dalexon Sérgio da SILVA* \\ Nadia Pereira Gonçalves de AZEVEDO** \\ Arthur de Araújo FILGUEIRAS***
}

\begin{abstract}
RESUMO: O presente trabalho analisa discursivamente um corpus constituído por uma matéria publicada pela revista Veja em 18 de abril de 2016, na qual se apresentam posições-sujeito de Marcela Temer, esposa de Michel Temer, o vice-presidente do Brasil, na época da reportagem. Assim, à luz da perspectiva teórica e dos procedimentos analíticos da Análise do Discurso de linha francesa (AD), este trabalho mobiliza o conceito de formação discursiva, sujeito, posições-sujeito e demais elementos constitutivos dessa linha de pesquisa, baseado, principalmente, nos estudos de Pêcheux (1997, 1999, 2014), Pêcheux e Fuchs (1993), Orlandi (1987, 2001, 2005, 2006, 2007), Foucault (2010), Fernandes (2008) e Mussalim e Bentes (2003), para mostrar como os sentidos estão à deriva e sempre escapam ao provocarem deslizamentos, ao serem inscritos noutras condições de produção do discurso.
\end{abstract}

PALAVRAS-CHAVE: Discurso. Posição-sujeito. formação discursiva.

ABSTRACT: The present work analyzes discursively a corpus constituted by an article published by Veja magazine on April 18, 2016, in which subject positions are presented by Marcela Temer, Michel Temer's wife, the vice president of Brazil, at the time of reporting . Thus, in the light of the theoretical perspective and analytical procedures of the Discourse Analysis of French Line (AD), this work mobilizes the concept of discursive formation, subject, subject-positions and other constituent elements of this line of research, based mainly on de Pêcheux (1997, 1999, 2014), Pêcheux and Fuchs (1993),

\footnotetext{
* Bolsista CAPES. Doutorando em Ciências da Linguagem pela Universidade Católica de Pernambuco - UNICAP. Membro do CLEPUL - Centro de Literaturas e Culturas Lusófonas e Europeias da Faculdade de Letras da Universidade de Lisboa e membro da Rede Latino-americana de Estudos Pentecostais - RELEP. E-mail: dalexon@uol.com.br

${ }^{* *}$ Doutora em Letras e Linguística pela Universidade Federal da Paraíba e Professora do Programa de Pós-graduação em Ciências da Linguagem pela UNICAP. E-mail: nadiaazevedo@gmail.com

*** Doutorando em Ciências da Linguagem pela Universidade Católica de Pernambuco - UNICAP e Professor da Faculdade dos Guararapes do Recife - PE. E-mail: arthurfilgueiras@yahoo.com.br
} 
Orlandi (1987, 2001, 2005, 2006, 2007), Foucault (2010), Fernandes (2008) and Mussalim and Bentes (2003), to show how the senses are Drift and always escape by causing slips. They are inscribed in other conditions of discourse production.

KEYWORDS: Discourse. Subject position. Discursive formation.

\section{Introdução}

A mídia ocupa um lugar de sujeito protagonista no cenário dos acontecimentos sociais, fazendo circular textos nos quais o analista de discurso pode perceber o funcionamento da ideologia. Assim, os grandes acontecimentos sociais são midiatizados e amplamente (re) construídos por intermédio da força e do poder influenciador da mídia em seu lugar de poder que ocupa ao enunciar.

Nesse entremeio entre língua, sujeito, história e ideologia, constitutivo na exterioridade, este trabalho destina-se a analisar uma matéria jornalística publicada pela revista Veja, em 18 de abril de 2016 (LINHARES, 2016) intitulada "Marcela Temer: Bela, recatada e do lar", adjetivos atribuídos a Marcela Temer, esposa do vice-presidente (na época) Michel Temer. Assim, este trabalho objetiva analisar como a revista Veja enuncia e mostra a posição-sujeito de esposa e a posição-sujeito de vice-primeira-dama, construídas discursivamente, para uma mulher que, supostamente, ocuparia essas posições. Vale salientar que, no que se refere à cena política da época, a presidenta Dilma Rousseff ocupava democraticamente a sua posição, enquanto o congresso previa um impeachment, supostamente baseado em contas de campanha com caixa dois. A mídia em geral veicula que desde o fim de 2014, há insatisfações do lado perdedor das eleições presidenciais.

Desse modo, baseado na perspectiva teórica e analítica da Análise de Discurso de linha francesa - $A D$, defendida, principalmente, por Pêcheux na Europa e por Orlandi e demais estudiosos no Brasil, este trabalho levanta e discute algumas questões: Como o discurso acerca da mulher é produzido e posto em circulação pela revista Veja? Que efeitos de sentidos são produzidos, pela revista Veja, a partir das posições-sujeito esposa e vice-primeira-dama ocupadas 
pela mulher Marcela Temer? Será que a revista Veja traz nesse discurso jornalístico um já-dito, cristalizado do que seria esperado de uma mulher "modelo" de primeira-dama, oposto, portanto, à posição-sujeito ocupada pela presidente Dilma Roussef, não bela (para os padrões sociais), guerrilheira, trabalhadora? Outra revista de grande circulação, a Isto É (06.04.2016 no 2417) traz em início do mês de abril de 2016 uma matéria, em que afirma estar o Brasil sendo governado por uma mulher descontrolada e autoritária, o que também pode ter gerado o efeito de que a oposição desejada pelo povo é a bela, recatada e do lar, publicado uma semana depois, na Veja. No mesmo mês, a Carta Capital se contrapõe ao enunciado da Veja, nomeando-o de antiquado, até para o século XIX.

\section{Discurso, sujeito, posição-sujeito e formação discursiva na Análise do Discurso de linha francesa}

Segundo Orlandi (2005), etimologicamente, a palavra discurso tem em si a ideia de curso, de percurso, de movimento. Nessa diretriz, o discurso é a palavra em movimento, de modo que o estudioso do discurso observa o homem falando em um processo de historicidade contínuo. O discurso, para Pêcheux e Fuchs (1993, p. 82), "é o efeito de sentidos entre locutores", pois o que é encontrado no discurso é um complexo processo de constituição de sujeitos e de produção de sentidos oriundos da tensão entre constituição e formulação. Os autores ainda salientam que o discurso é estrutura e acontecimento. Fernandes (2008) atestou que, devido ao fato de os discursos terem sua legitimidade assegurada no já-dito, na memória, eles não são fixos, mas se transformam e assumem outros valores, de acordo com a época, o lugar e a ideologia vigente.

Nesse item, o discurso é definido como um fenômeno constituído não apenas por elementos linguísticos, mas por elementos extralinguísticos. Destes, o conceito de ideologia é aquele com que o discurso mantém uma relação mais direta. Assim, Pêcheux (1988) propõe que o discursivo seja entendido como uma 
das formas da materialidade das ideologias. Sendo assim, concebe as formações discursivas (FD) como elementos constitutivos das formações ideológicas (FI), as quais estão relacionadas à produção dos discursos.

Do exposto, a Análise de Discurso compreende o sujeito como sendo atravessado tanto pela ideologia quanto pelo inconsciente. Nesse enfoque seu sujeito não é uno ou do cogito, mas é considerado um sujeito descentrado, cindido, clivado. Ele não se constitui na fonte e origem dos processos discursivos que enuncia, pois esses processos são determinados pela formação discursiva na qual o sujeito falante se inscreve, embora esse sujeito possua a ilusão de ser a fonte ou origem do seu discurso. De acordo com Mussalim e Bentes (2003), o discurso se inscreve num terreno em que intervêm questões teóricas relativas à ideologia e ao sujeito.

Com efeito, é inserido nessa concepção de que o sujeito não é o senhor de sua vontade, levando-se em consideração que ele sofre as coerções de uma formação ideológica e discursiva, ou é submetido à sua própria natureza inconsciente, que emerge a questão da interpelação ou do assujeitamento do sujeito como sujeito ideológico, que consiste em fazer com que cada sujeito, sem que tenha consciência disso, mas, ao contrário, tenha a impressão de que é o senhor de sua própria vontade, seja levado a ocupar seu lugar determinado em um dos grupos ou classes.

Mediante o exposto, fica evidenciado que, para a Análise do Discurso de linha francesa, o sujeito não é origem do sentido, nem elemento de onde se origina o discurso. Ressalta-se a compreensão de que ele não é único, pois há diversas posições-sujeito que estão relacionadas com determinadas formações discursivas e ideológicas. Nessa guisa, o sujeito está sempre interpretando e, ao interpretar, produz sentido, inscrevendo-se numa Formação Discursiva para enunciar.

O conceito de Formação Discursiva (FD) foi criado por Foucault (2010) e desenvolvido por Pêcheux e Fuchs (1993) em suas concepções teóricas acerca da Formação Discursiva. Pêcheux e Fuchs (1993) busca centralizar suas 
pesquisas, destacando o elemento ideológico, já que, em sua compreensão, a ideologia é materializada no discurso. Assim, para Pêcheux, a FD está, pelo menos em seu início, intimamente relacionada à noção de formação ideológica, uma influência da obra "Ideologia e Aparelhos Ideológicos do Estado", de Althusser, o que, por conseguinte, explica o seu estreito laço com o Marxismo. Assim Pêcheux expõe seu conceito:

chamaremos, então, formação discursiva aquilo que, em uma formação ideológica dada, isto é, a partir de uma posição dada em uma conjuntura dada, determinada pelo estado da luta de classes, determina "o que pode e o que deve ser dito", articulado sob a forma de uma alocução, de um sermão, de um panfleto, de uma exposição, de um programa, etc. (PÊCHEUX, 1997, p. 160)

Dessa forma, ao chegar a essa concepção de formação discursiva, o autor compreende que a diferença entre duas Formações Discursivas está contemplada no elemento ideológico, nas lacunas que favorecem a movimentação e impedem a cristalização dos sentidos. Assim,

as formações ideológicas de que acabamos de falar comportam necessariamente, como um de seus componentes, uma ou várias formações discursivas que determinam o que pode e deve ser dito (articulando sob a forma de uma arenga, um sermão, um panfleto, uma exposição, um programa, etc) a partir de uma posição dada numa conjuntura, isto é, numa certa relação de lugares num interior de um aparelho ideológico, e inscrita numa relação de classes (PÊCHEUX; FUCHS, 1993, p. 166).

Do que foi dito, pode-se observar nas palavras de Pêcheux a presença da heterogeneidade da Formação Discursiva (FD). Ele prossegue com essas reflexões e comprova que, no interior de uma FD, coexistem discursos provenientes de outras formações discursivas, o que implica o favorecimento da diferença e da contradição, como características constitutivas de uma FD, na compreensão de que os discursos fazem parte de formações ideológicas e discursivas, associadas, sempre, a uma memória social. Isto é, o autor defendeu a ideia de que toda formulação possui, em seu "domínio associado", outras 
formulações que ela repete, refuta, transforma, nega, enfim, em relação às quais se produzem certos efeitos de memória específicos. Trata-se, portanto, de inserir no coração da noção de Formação Discursiva a problemática da memória, cujo trabalho produz a lembrança ou o esquecimento, a reiteração ou o silenciamento de enunciados. Mussalim e Bentes (2003, p. 119) acrescenta a tal assertiva, a compreensão de que:

uma formação discursiva determina o que pode/deve ser dito a partir de um determinado lugar social. Assim uma formação discursiva é marcada por regularidades, ou seja, por "regras de formação", concebidas como mecanismos de controle que determinam o interno (o que pertence) e o externo (o que não pertence) de uma formação discursiva.

Logo, Mussalim e Bentes (2003) destaca que as formações discursivas sempre se correspondem com outras Formações Discursivas para a sua concepção. Isto é, baseiam-se em outras Formações Discursivas para elaborarem seu próprio discurso. Nessa perspectiva, uma Formação Discursiva é atravessada pelo pré-construído, definição evidenciada por Pêcheux, que ele define como discursos que vieram de outro lugar e que são incorporados por ela em uma relação de confronto ou aliança.

Pêcheux (1997) compreende que a formação discursiva é o lugar de articulação entre língua e discurso. Assim, as palavras, expressões, proposições possuem sentido a partir da formação discursiva na qual são produzidas. É nesse trâmite que o conceito de Formação Discursiva é trabalhado pela $A D$ para designar o lugar onde se articulam discurso e ideologia.

\section{Aspectos metodológicos}

O corpus deste trabalho é composto por uma matéria da revista Veja, datada de 18 de abril de 2016 e acessada no site da revista Veja Online em 22 de maio de 2016, com uma reportagem sobre as qualidades da vice-primeiradama Marcela Temer. A matéria tem como título: "Marcela Temer: bela, recatada 
e do lar" (LINHARES, 2016). A seleção do corpus discursivo foi realizada, conforme explicitado na introdução do trabalho, pelo impacto que o enunciado gerou na opinião pública, visto se tratar de uma ideologia machista, antiquada. A reportagem completa foi impressa, depois escaneada e se encontra exposta em três páginas anexadas ao final deste artigo, visando oferecer aos leitores 0 acesso à versão integral da matéria. Aqui, coube analisar, pelo viés da $A D$, os recortes discursivos selecionados da matéria, nos quais aparecem mais marcados os elementos constitutivos da posição-sujeito da mulher esposa e da posiçãosujeito da mulher vice-primeira-dama. Para tal, este trabalho mobilizou, principalmente, as contribuições de Pêcheux e Fuchs (1993), Pêcheux (1997, 1999, 2014) e Orlandi $(1987,2001,2005,2006,2007)$, dentre demais estudiosos da Análise de Discurso de linha francesa.

\section{Trabalho analítico num corpus discursivo}

De acordo com Orlandi (1987, p. 139-140), "O recorte é uma unidade discursiva: fragmento correlacionado de linguagem - e - situação $[. .$.$] os recortes$ são feitos na (e pela) situação de interlocução, aí compreendido um espaço menos imediato, mas também de interlocução, que é o da ideologia". Assim, seguem, abaixo, os recortes discursivos analisados da matéria da revista.

Nesse viés, logo de início, destacam-se alguns adjetivos, no título da matéria, atribuídos a Marcela Temer: "Bela, recatada e do lar". Assim, levandose em consideração que, de acordo com Pêcheux (2014) e Mussalim e Bentes (2003), o discurso é estrutura e acontecimento, pois o linguístico intervém como pressuposto, apontando para a exterioridade; e é acontecimento porque promove o encontro de uma memória atual e uma rede de memórias, pode-se observar que as marcas linguísticas atribuídas a Marcela Temer: "bela, recatada e do lar", carregam o social, o ideológico e o histórico da posição-sujeito construída discursivamente para ela na revista Veja. Dito de outro modo, os três atributos podem apontar noutro lugar para: "não reclama, está sempre sorrindo 
e nunca bateria de frente com o marido". Dessa forma, marcando a posiçãosujeito da mulher esposa, como um lugar decorativo e passivo.

Desse modo, o termo linguístico: "bela"promove, neste texto jornalístico da revista, o atravessamento do discurso estético, que visa a espetacularizar determinados padrões de beleza, fortalecendo os produtos cosméticos. Tal efeito de aprovação estética vem reforçado pela produção do efeito de gradação, ao se seguir das marcas linguísticas: "recatada e do lar". Assim, produzem-se efeitos de sentidos crescentes, além de "bela", ela é "recatada e do lar". Sendo o sentido para a Análise do Discurso de linha francesa sempre construído numa relação determinada do sujeito com a história, pode-se apontar que: "recatada e do lar", presente na superfície desse texto, faz ressoar ecos de outro lugar, da exterioridade, como bem pontua Pêcheux (1999), ao dizer que alguma coisa fala antes, em outro lugar, independentemente e diferentemente. Logo, são resquícios de ranços na historicidade que apontam para momentos nos quais esses eram os atributos padrões idealizados pelas mulheres, na sociedade, para conseguirem ter um bom casamento em suas práticas sociais. Dito isso, pode-se questionar o efeito de estranhamento e de protestos que o título desta matéria: "Marcela Temer: Bela, recatada e do lar", provocou nos brasileiros, de uma maneira geral, após a publicação.

Nas formações discursivas da atualidade, as mulheres do Brasil não estão identificadas a esses atributos como critérios imperativos para uma mulher. Elas não estão interessadas, de forma imperativa, em ser belas para o homem, ou recatadas, puras, ingênuas e, muito menos, do lar, para esperar por seu marido e servi-lo. É pertinente ressaltar que este trabalho destaca os efeitos de sentidos, pois, para Pêcheux e Fuchs (1993), o discurso também é visto como o efeito de sentidos entre locutores, sendo assim, é pertinente apontar como essa matéria jornalística produz tais efeitos.

Logo abaixo do título da matéria, o texto segue assim: "A quase primeiradama, 43 anos mais jovem que o marido, aparece pouco, gosta de vestidos na altura dos joelhos e sonha em ter mais um filho com o vice". Orlandi (2007) nos 
diz que, ao se assumir uma posição, está-se apagando, necessariamente, outro sentido que circula numa formação discursiva antagônica. Logo, ao se mostrar os gostos da mulher Marcela que ocupa a posição-sujeito de esposa recatada: "gosta de vestidos na altura dos joelhos e sonha em ter mais um filho com o vice", apagam-se as posições-sujeito de esposas que são posições indesejáveis pela revista Veja na construção discursiva da posição-sujeito esposa, mostrada nesta matéria jornalística (a de esposas que não possuem o padrão de beleza normatizado pela indústria estética, a de esposas efusivas que não são recatadas, a de esposas que trabalham fora de casa, porque, acima de tudo, é dessa forma que se realizam. Desse modo, dá-se a construção de sentidos desta matéria pelo atravessamento do silêncio constitutivo, termo este, alcunhado por Orlandi (2007) e que remete a um dizer " $X$ " que apaga um dizer " $Y$ ". Logo, o termo "recatada" silencia outros sentidos como o de uma mulher contemporânea e emancipada.

Em seguida, a matéria de Veja diz: "Há cerca de oito meses, por exemplo, o vice-presidente, de 75 anos, levou Marcela, de 32, para jantar na sala especial do sofisticado, caro e badalado restaurante Antiquarius, em São Paulo". Do exposto, mais uma vez, é produzido o efeito de gradação: o restaurante que o casal frequenta é apresentado como "sofisticado, caro e badalado". Como efeitos de sentido, temos que a mulher bela, recatada e do lar opta por restaurantes nada populares, o que parece fazer parte da FD da mulher do vice-presidente. Tais marcas linguísticas não produzem sentidos em si mesmas, mas apontam, na exterioridade, para uma esfera social, a das mulheres que ocupam a posiçãosujeito de esposas ricas. Dito de outro modo, ao marcar esta posição de esposa, a revista Veja está também apagando a posição-sujeito de esposa da classe pobre, que não frequenta um restaurante com esses atributos, pois Marcela é mostrada na reportagem de Veja como uma mulher da classe média alta, sendo o motivo pelo qual se produz o efeito de espetacularização de Marcela nesta reportagem. 
Isto é, os saberes mostrados pela revista Veja, como pertencentes a uma mulher que ocupa a posição-sujeito de esposa rica, visa a fazer ressaltar no discurso jornalístico identificado à linha editorial desta revista, o efeito de legitimidade e de confiabilidade, pois, de acordo com a reportagem, Marcela é a mulher idealizada ao ocupar essa posição-sujeito de esposa, esse lugar construído discursivamente por Veja.

Tal exposição nos faz lembrar o que defende Orlandi (2006), ao dizer que a ideologia naturaliza os valores da classe dominante. Assim, é na relação do sujeito com a exterioridade mediada por práticas sociais que se pode compreender os processos de significação no funcionamento da ideologia materializada no discurso. Noutro momento, a revista produz efeitos de sentido paradoxais e vagos, ao atribuir mais adjetivos a Marcela Temer (bacharel em Direito, sem nunca ter exercido a profissão, Curriculum Vitae com certo período de trabalho e dois concursos de miss no interior de São Paulo). Logo, fica evidenciado que, embora a revista Veja possua o poder em sua posição de enunciar, ela não possui o poder de controlar os sentidos, mantendo-os ensimesmados, pois, segundo Orlandi (2007), os sentidos sempre estão à deriva. Assim, sempre se constroem com ecos históricos, ressoando acontecimentos já passados.

Desse modo, na malha do discurso jornalístico mostrado por Veja, escondem-se efeitos de sentido que se historicizam e trazem memórias que provocam efeitos de sentido contrários aos "belos" adjetivos atribuídos a Marcela Temer em suas posições-sujeito. Esse efeito se dá pelo fato de que o discurso é atravessado pelas falhas, opacidades, contradições que lhe são constitutivas, ou, em outras palavras, por sua heterogeneidade. Com esse mesmo enunciado, "Bela, recata e do lar", encontramos nas redes sociais, diversas fotografias de mulheres em bares bebendo e fumando e praticando atividades musculares. Dessa mesma forma, encontramos deslizamentos a produção de efeitos de sentido como "Fera, desbocada e do bar". 
Pêcheux e Fuchs (1993), Orlandi (2005) e Mussalim e Bentes (2003) nos mostram que o sujeito da Análise de Discurso de linha francesa é um lugar. Logo, ao serem analisadas a estrutura, o acontecimento e as condições de produção desta matéria, que marca o lugar no qual Marcela Temer é apresentada por Veja, em sua posição-sujeito de esposa rica do Michel Temer, esse trabalho analítico apresenta os seguintes quadros ${ }^{1}$ que marcam bem as posições-sujeito inseridas em suas respectivas formações discursivas e, constitutivamente, ideológicas, construídas discursivamente pela revista Veja para o lugar de Marcela e as posições-sujeito que foram silenciadas na matéria analisada:

Quadro 1- Posição-sujeito da mulher esposa

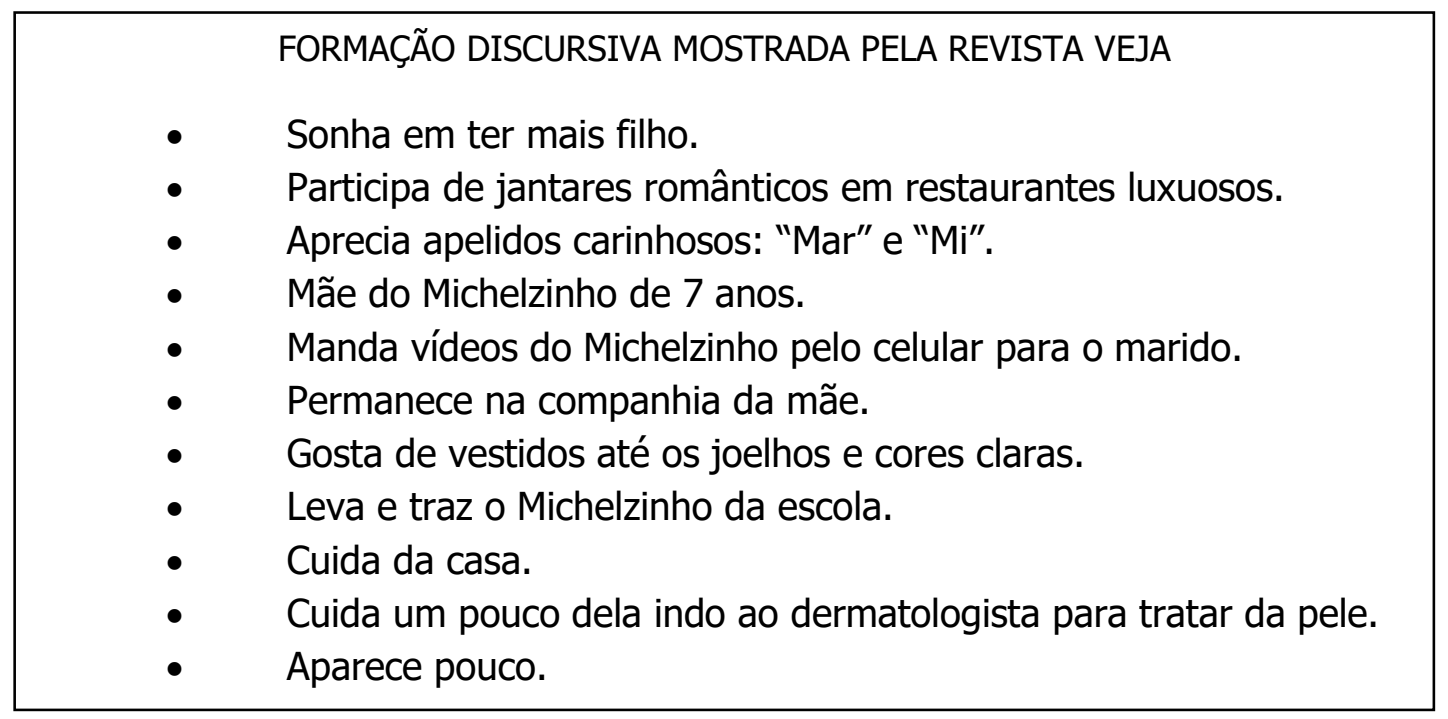

Quadro 2- Posição-sujeito da mulher esposa

\section{FORMAÇÃO DISCURSIVA SILENCIADA PELA REVISTA VEJA}

- Posição-sujeito de mulher trabalhadora

- Pode escolher não ter filhos

- Prefere jantar em locais menos sofisticados e mais populares.

- Não tem mais filhos, porque não tem condições financeiras para mantê-los.

- Permanece na companhia das amigas do trabalho. Escolhe as próprias roupas de acordo com a ocasião

- Divide com o marido a responsabilidade da casa.

- Não tem plano de saúde e passa meses esperando uma consulta do SUS para se tratar de alguma doença.

- É extrovertida e adora dar gargalhadas. revista, nas diferentes FD. 
Quadro 3- Posição-sujeito da mulher vice-primeira-dama FORMAÇÃO DISCURSIVA MOSTRADA PELA REVISTA VEJA

- É o braço digital do vice, pois está constantemente de olho nas redes sociais para Ihe informar sobre a temperatura ambiente.

Quadro 4- Posição-sujeito da mulher vice-primeira-dama

$$
\text { FORMAÇÃO DISCURSIVA SILENCIADA PELA REVISTA VEJA }
$$

- Tem conhecimento de economia interna e externa.

- É elaboradora de projetos sociais.

- Tem domínio de políticas públicas internacionais.

- É uma boa articuladora política.

- Tem uma boa desenvoltura administrativa burocrática e de relações pessoais.

- É poliglota com desenvoltura para representar o Brasil no exterior.

- Trabalhou durante muitos anos ajudando em causas sociais favorecendo às pessoas mais pobres.

Tais tabelas mostram como a revista Veja marca sua posição ao enunciar a função que a mulher Marcela Temer ocupa como esposa; contudo, ao enunciar, na ilusão, como se fosse fonte e origem do dizer, a revista Veja produz efeitos de sentido negativos, paradoxais, ao quase esgotar o seu estoque de adjetivos, atribuindo-os a Marcela Temer, que é mostrada inscrita discursivamente na posição-sujeito de "esposa ideal", pois a revista não pode controlar os sentidos, que são históricos e sempre estão em movimentos. Logo, tais adjetivos (marcas linguísticas) atribuídos a Marcela (sonha em ter mais filho, aparece pouco, participa de jantares românticos em restaurantes luxuosos, aprecia apelidos carinhosos: "Mar" e "Mi", mãe do Michelzinho de 7 anos, manda vídeos do Michelzinho pelo celular para o marido, permanece na companhia da mãe, gosta de vestidos até os joelhos e cores claras, leva e traz o Michelzinho da escola, 
cuida da casa, cuida um pouco dela indo ao dermatologista para tratar da pele), funcionam como pressupostos que apontam, na historicidade, para o sóciohistórico.

Do que foi dito, acerca da historicidade e dos sentidos, Orlandi (2001) reforça que os sentidos são históricos e estão sempre em movências. Dito isso, os termos linguísticos atribuídos à "esposa ideal" Marcela, não funcionam no texto, apenas, como qualificadores atribuídos pela revista, mas escapam e deslizam, fazendo referências, na exterioridade, à posição-sujeito de esposa rica, que aprecia restaurante da alta sociedade, marcando bem esse lugar ocupado por Marcela Temer, enquanto sujeito desejante dos gostos nobres da alta sociedade.

Pêcheux (2014) aborda o modo como o sujeito pode estar em relação à formação discursiva, como identificado, contra-identificado ou desidentificado. 0 primeiro representa o sujeito que está identificado a uma formação discursiva. É o "bom sujeito", "assujeitado, ligado ao inconsciente, e tem o processo de identificação à formação discursiva de forma livre ou ainda de forma assujeitada inconscientemente. Já o segundo representa o sujeito contra-identificado a uma formação discursiva. Ele questiona saberes pertencentes à sua formação discursiva dominante mas permanece identificado a ela. $O$ terceiro modo, por sua vez, corresponde à desidentificação do sujeito do discurso com a formação discursiva dominante em que está inscrito, abandonando-a e se inscrevendo em uma nova.

Nesse item, a matéria de Veja provocou e fez reverberar, em todo o Brasil, vários efeitos de sentido de protestos de outras mulheres que ocupam a posiçãosujeito de esposas, mas não estão identificadas à formação discursiva na qual Marcela Temer foi mostrada por Veja. Assim, "a posição-sujeito esposa ideal de Veja", é aquela ocupada por uma mulher branca, rica, de valores requintados e de comportamentos de práticas tradicionais que apontam para as práticas do início deste século. 
É pertinente ressaltar que todos esses efeitos qualificadores produzidos por Veja e atribuídos à posição-sujeito de "esposa ideal", visa a produzir um forte efeito de sentido de justificação, para legitimar que Marcela Temer seria uma primeira-dama perfeita se viesse a ocupar essa posição-sujeito, pois, segundo a matéria, Marcela possui, dentre outras, as qualidades de ser discreta, falar pouco e usar saias na altura do joelho. Dito de outro modo, ela é bela, recatada e do lar. Há, desse modo, um deslizamento de sentidos que deriva da posição-sujeito ocupada pela presidente do Brasil, à época da matéria, que não é bela (para os padrões estéticos sociais), não é recatada, uma vez que lutou contra o golpe militar e foi guerrilheira, bem como não é do lar, visto que ocupa o mais alto posto do governo, sem o apoio de um homem, distanciando-se do padrão patriarcal da mulher como auxiliadora do homem, em posição lateralizada. A matéria visa a estabelecer este contraponto entre as duas posições-sujeito, o que também se pôde observar a partir do já descrito anteriormente, a respeito da então presidenta Dilma, pela revista Isto é (06.04.2016 no 2417) e ainda pela crítica à revista Veja feita pela Carta Capital do mesmo ano.

Desta forma, é relevante destacar que as reações de protestos - com críticas e ironias, sobretudo por meio de memes, nas redes sociais da internet,produzidas por diversas brasileiras, que ocupam a posição-sujeito de esposas e se viram desidentificadas dessa formação discursiva de "esposa ideal de Vejd", não se deram pelo motivo de que uma esposa não possa ser "bela, recatada e do lar", caso ela se inscreva nesta formação discursiva, mas, antes disso, porque a matéria de Veja produziu o efeito de sentido de normatizar este lugar como o "ideal", silenciando outros saberes e sentidos. Dentre outros possíveis sentidos, a posição-sujeito de mulher trabalhadora, que pode escolher não ter filhos, não ter um segundo filho, por outros motivos, jantar em locais menos sofisticados, permanecer na companhia das amigas do trabalho, escolher as próprias roupas de acordo com a ocasião, dividir com o marido a responsabilidade da casa, ser extrovertida, adorar dar gargalhadas etc. 
É necessário pontuar que a matéria de Veja provocou uma resposta em cadeia nas redes sociais, em que as mulheres, ao se sentirem agredidas pela reportagem, postavam fotos no trabalho, ou com roupas decotadas, com amigos, com o mesmo slogan, enquanto, por vezes, o título era "feia, desbocada e do bar". A mulher não mais admite rótulos que a aprisionem a alguém passivo, que nasceu, apenas, para ser "esposa". Esses protestos na internet se deram porque esse meio de comunicação ganhou no mundo atual o lugar de praça pública, e não só para este assunto, mas para qualquer tema. Assim, as redes e os grupos organizados que estão presentes, nesse mundo virtual, têm voz nessa grande praça pública. Contudo, é pertinente pontuar que, ao se falar em "mulher brasileira", ela não é uma, mas é complexa, pois há mulheres com formações discursivas diversas, dentre as quais as belas, recatadas e do lar.

É interessante observar que este imaginário social apresentado pela reportagem de Veja está bem presente na sociedade brasileira, mas representa um país que não está visível, que não está nas redes, que vive e reverbera no imaginário social. Basta que nos lembremos dos nossos congressistas, quando foram votar pelo impeachment, evocaram a família e a Igreja, o que pode ter funcionado como memória discursiva para o título em análise na reportagem. Uma formação discursiva do século passado, em que a sociedade e a própria mulher defendiam ser bela, recatada e do lar.

Ainda se torna pertinente destacar que no que se refere à posição-sujeito de vice-primeira-dama, a revista Veja não apresenta os mesmos turbilhões qualificativos atribuídos à posição-sujeito de esposa para Marcela Temer, favorecendo o deslizamento de sentidos de que a posição-sujeito de esposa the dará aptidões para que ela possa assumir a posição-sujeito de primeira dama do Brasil. Assim, ao marcar a posição de vice-primeira-dama do Brasil, a revista Veja, diz: "É o braço digital do vice, pois está constantemente de olho nas redes sociais para Ihe informar sobre a temperatura ambiente". Pode-se observar, a partir deste enunciado em destaque, que o funcionamento da ideologia na matéria do semanário em análise produz o efeito de obviedade. Assim, naturaliza o lugar 
construído para Marcela Temer, que pode ser inscrita na posição de primeiradama do Brasil, apagando, desse modo, outros saberes e silenciando sentidos provenientes de outras formações discursivas do lugar de primeira-dama. Tem conhecimento de economia interna e externa, é elaboradora de projetos sociais, tem domínio de políticas públicas internacionais, é uma boa articuladora política, tem uma boa desenvoltura administrativa burocrática e de relações pessoais, é poliglota com desenvoltura para representar o Brasil no exterior, trabalhou durante muitos anos ajudando em causas sociais favorecendo às pessoas mais pobres.

\section{Considerações Finais}

A Revista Veja traz um já-dito, cristalizado, acerca da posição-sujeito da mulher, como aquela que "não reclama, está sempre sorrindo e nunca bateria de frente com o marido". Assim, marca a posição-sujeito da mulher esposa e da mulher vice-primeira-dama como um lugar decorativo e de passividade. Desta forma, a Revista demonstrou enunciar numa ilusão de centralidade e de originalidade, enquanto formuladora de enunciados, ao apresentar esta matéria sobre a posição-sujeito de esposa e de vice-primeira-dama, ocupadas por Marcela Temer, esposa do vice-presidente (na época da matéria) Michel Temer, pois os sentidos originais pretendidos pela revista escaparam e reverberaram em protestos por todos os lugares do Brasil.

Fernandes (2008) já atestou que, devido ao fato de os discursos terem sua legitimidade assegurada no já-dito, na memória, eles não são fixos, mas se transformam e assumem outros valores, de acordo com a época, o lugar e a ideologia vigente. Nesse viés, analisou-se como essa matéria jornalística produz efeitos de sentidos, marcando o lugar da mulher numa posição-sujeito que seria aceitável amplamente pela sociedade, como "dona de casa, mãe, esposa e apaixonada", contudo, como em todo enunciado há deslizes e falhas, essa matéria de Veja, ao ser inscrita na historicidade, apontando para a exterioridade, produziu efeitos de sentidos negativos, de protestos com ironias e duras críticas, 
manifestadas pelas mulheres brasileiras que ocupam a posição-sujeito de esposas, pelo fato da revista objetivar normatizar essa posição-sujeito como a ideal na nossa atual sociedade.

Desse modo, para produzir o efeito de sentido de legitimidade na matéria, a revista Veja faz uso abundante de adjetivos (marcas linguísticas que apontam para exterioridade) atribuídos, qualitativamente e gradativamente, a Marcela Temer, provocando um forte efeito de espetacularização da posição-sujeito de "esposa ideal" ocupada pela Marcela e que, por isso, reunia atributos necessários para poder ocupar perfeitamente outra posição-sujeito, criada discursivamente pela revista, a de primeira-dama do Brasil. Isso no funcionamento da ideologia presente no modo de enunciar de Veja, que ainda qualifica Michel Temer, no final da matéria, como um homem de sorte.

Dito de outro modo, Marcela encaixa-se perfeitamente nas "qualidades" que a sociedade patriarcal espera de uma mulher. Isto é, uma esposa dedicada e que vive à sombra do marido, boa mãe e uma mulher esteticamente atraente, muito identificada, estritamente, ao âmbito doméstico. Logo, nessa construção social de sentidos, reverberaram os efeitos de sentidos contraditórios em relação a essa matéria, pois, na atualidade, há uma heterogeneidade de formações discursivas na posição-sujeito de esposa, ocupadas pelas mulheres modernas que promovem uma movência na rede de filiação de sentidos e saberes, permitindoIhes se identificarem, contra-identificarem ou se desidentificarem deste lugar social construído discursivamente pela revista Veja para Marcela Temer, como "esposa ideal" (mostrado nos quadros acima neste artigo) e se identificarem a outras formações discursivas sem, sem deixarem de ser: "Belas, recatadas e do lar".

\section{Referências}

FERNANDES, Claudemar Alves. Análise do discurso: reflexões introdutórias. Goiânia: Trilhas Urbanas, 2008. 
FOUCAULT. $A$ arqueologia do saber. Rio de Janeiro: Forense, 2010.

LINHARES, Juliana. Marcela Temer: bela, recatada e do lar. Veja, 18 abr. 2016. Disponível em: <http://veja.abril.com.br/brasil/marcela-temer-bela-recatada-edo-lar/>. Acesso em: 2 abr. 2017.

MUSSALIM, Fernanda; BENTES, Anna Christina (Org.). Introdução à linguística: domínios e fronteiras. São Paulo: Cortez, 2003. v. 3.

ORLANDI, Eni P. Análise do Discurso: princípios \& procedimentos. São Paulo: Pontes, 2005.

Pontes, 2001.

. Discurso e texto: formação e circulação dos sentidos. Campinas:

. Palavra, fé, poder. Campinas: Pontes, 1987.

. As formas do silêncio: no movimento dos sentidos. Campinas: Editora da Unicamp, 2007.

. A Linguagem e seu funcionamento: as formas do discurso. Campinas: Pontes, 2006.

PÊCHEUX, Michel; FUCHS, C. A propósito da análise automática do discurso: atualização e perspectivas. In: GADET, F.; HACK, T. (Org.). Por uma análise automática do discurso: uma introdução à obra de Michel Pêcheux. Campinas: Editora da Unicamp, 1993.

PÊCHEUX, Michel. O discurso: Estrutura ou acontecimento. 2. ed. São Paulo: Pontes, 1997.

. Papel da memória. In: ACHARD, P. et AL. (Org.). Papel da memória. Tradução e introdução de José Horta Nunes. Campinas: Pontes, 1999, p. 49-57.

. Semântica e discurso: uma crítica à afirmação do óbvio. Tradução E. Orlandi et al. 5. ed. Campinas: Editora da Unicamp, 2014. 
Bela, recatada e do lar: uma análise discursiva das posições-sujeito da mulher na revista Veja

ANEXO - REPORTAGEM SCANNEADA DA REVISTA VEJA ON LINE 
Bela, recatada e do lar: uma análise discursiva das posições-sujeito da mulher na revista Veja

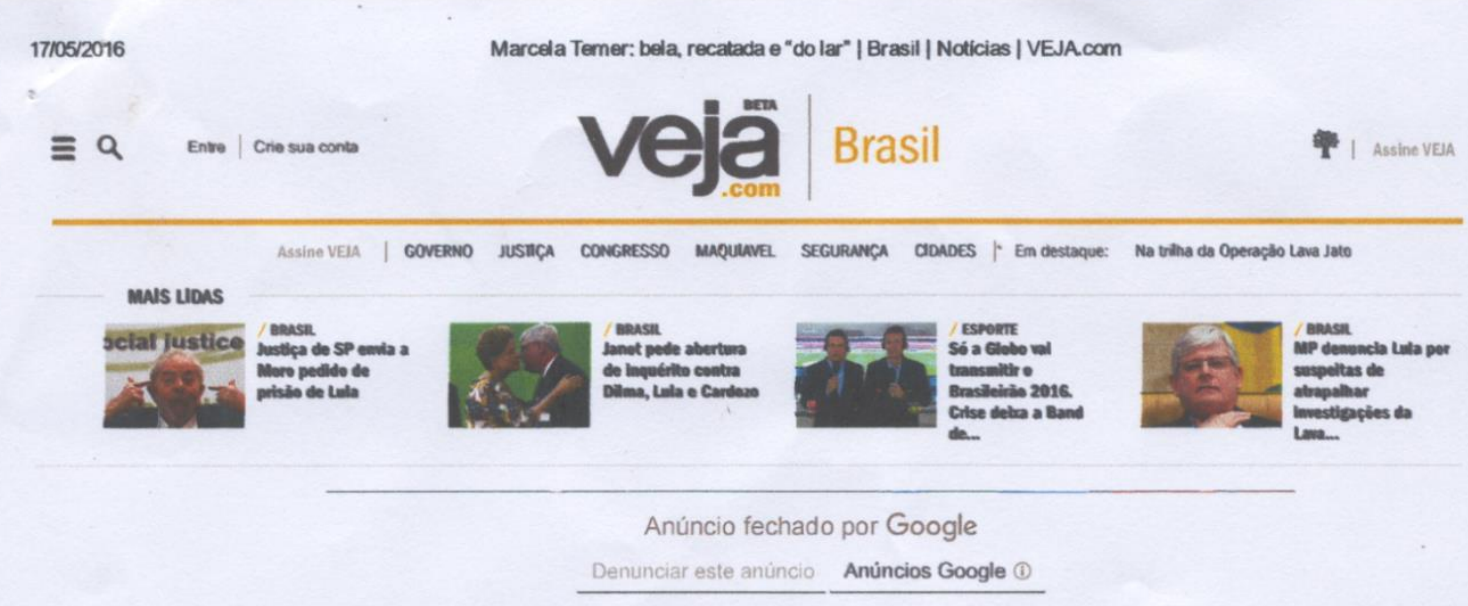

XBRASIL.

\section{Marcela Temer: bela, recatada e "do lar"}

A quase primeira-dama, 43 anos mais jovem que o marido, aparece pouco, gosta de vestidos na altura dos joelhos e sonha em ter mais um filho com o vice

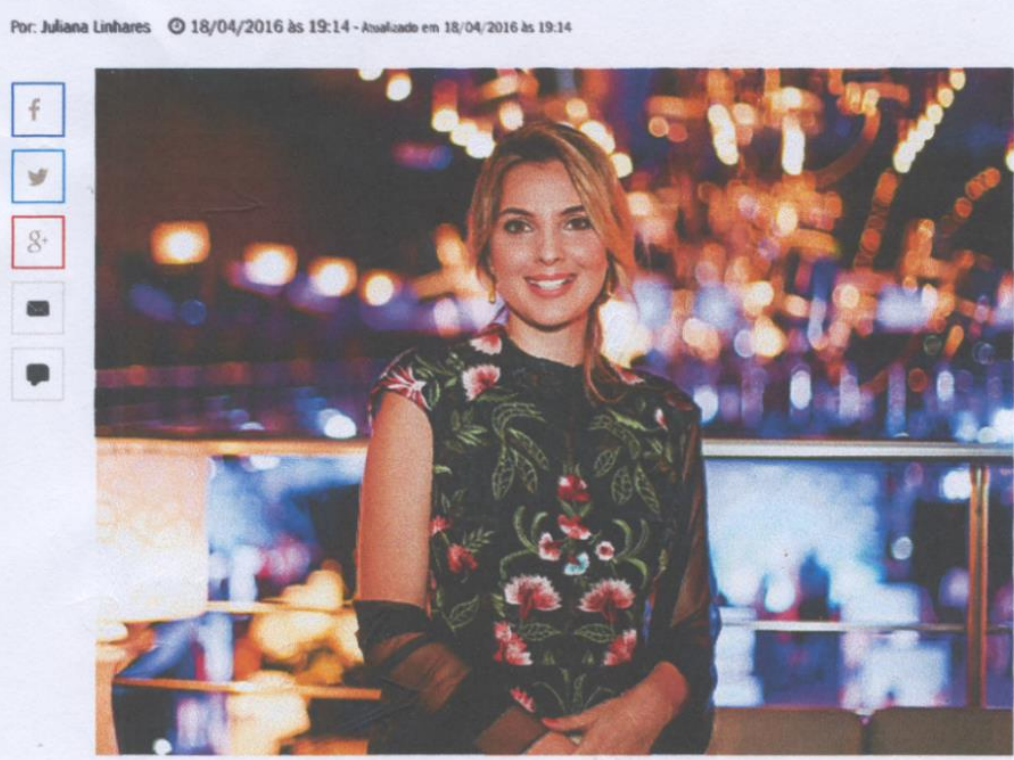

Marcela, mullher do vice, Miched Temer. jantares romalnticos e apelidos carinhosos (Bruno Poletti/Follhapress)

Marcela Temer é uma mulher de sorte. Michel Temer, seu marido há treze anos, continua a the dar provas de que a paixão não arrefeceu com o tempo nem com a convulsảo politica que vive o pais - e em cujo epicentro ele mesmo se encontra. Há cerca de oito meses, por exemplo, o vice-presidente, de 75 anos, levou Marcela, de 32, para jantar na sala especial do sofisticado, caro e badalado restaurante Antiquarius, em São Paulo. Blindada nas paredes, no teto e no chão para ser à prova de som e garantir os segredos dos muitos políticos que costumam reunir-se no local, a sala tem capacidade para acomodar trinta pessoas, mas foi esvaziada para receber apenas "Mar" e "Mi", como são chamados em familia. Lá, protegido por quatro seguranças (um na cozinha, um no toalete, um na entrada da sala e

$=23 / 06 / 2016$ Rio de lanciroGaleãoRecifecompre aquiA parti 10xRS65.18-10/06/2016Rio de. GaleãoRecifecompre aquiA part 10xRS68.48-20/05/2016Rio de GaleãoRecifecompre aquiA part 10xRS100.58=10062016Rio d GaleãoRecifecompre aquiA part 10xRS75,98-21/10/2016Rio de GaleãoRecifecompre aquiA parti 10xRS 115.88

Pela Web

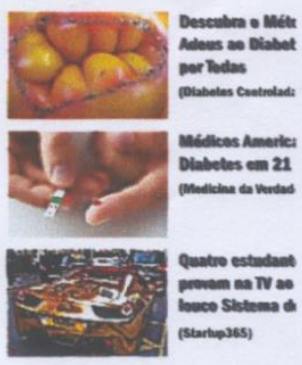

Recomendados para Você

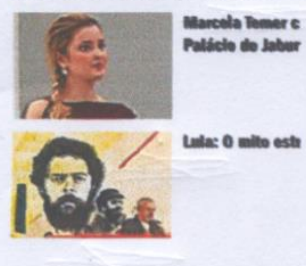


Bela, recatada e do lar: uma análise discursiva das posições-sujeito da mulher na revista Veja

outro no salīo principal do restaurante), o casal desfintou algumas horas dejantar romântico sob um céu estrelado, graças ao teto retrátil do ambiente. Marcela se casou com Temer quando tinha 20 anos. 0 vioe, então com 62, estava no quinto mandato como deputado federal e foi seu primeiro namorado.

Michelrinhe, de 7 anøs, cabelo tigelinhtr e uma hela janehr ne lugar que abriganá seus imcisivos centrais,

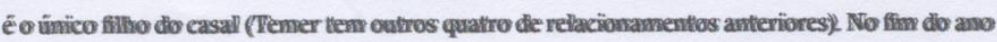
passado, Marcela pensou que esperava o segundo filho, mas foi um alarme falsa. No final, eles schlaram que não teria sido mesmo um bom momento para cla engravidar, dada a confusão no pais", conta tia Nina, imã da mäe de Marcela. Ela se refez do sobressalta, mas não se resignou - ainda quer ter uma menininha. No Carnaval, Marcela planejou uns dias de sol e praia só com o marido e o filho e foi para a Riviera de São Lourenço, no Litoral Norte de São Paulo. Temer iria depois, mas, nos dias seguintes, 0 plano foi a pique: o vice ligou, dizendo que estava receoso de expor a familia, devido aos ânimos acirrados no pais. Pegou Marcela, Michelzinho, e todo mundo voltou para casa.

Bacharel em direito sem nunca ter exercido a profissão, Marcela comporta em seu curriculum vĩtoe um curto periodo de trabalho como recepcionista e dois concursos de miss no interior de São Paulo (representando Campinas e Paulinia, esta sua cidade natal). Em ambos, ficou em segundo lugar. Marcela é uma vice-primeira-dama do lar. Seus dias consistem em levar e trazer Michelzinho da escola,

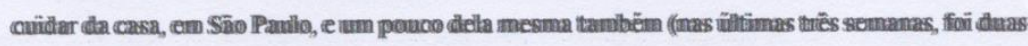
vezes à dermatologista tratar da pele).

Por algum tempo, frequentou o salão de beleza do cabeleireiro Marco Antonio de Biaggi, famosø pela clientela estrelada. Pedia luzes bem fininhas e era "educadissima", lembra o cabeleireira. "Assim came faz a Athina Onassis quando vem ao meu salão, ela deixava os seguranças do lado de fora", informa Biaggi. Na opinião do cabeleireiro, Marcela "tem tudo para se tornar a nossa Grace Kelly". Para iss, falta só "deixar o cabelo preso". Em todos esses anos de atuação política do marido, ela apareceu em público pouquissimas vezes. "Marcela sempre chamou atenção pela beleza, mas sempre foi recataudal, diz sua irmã mais nova, Fernanda Tedeschi. "Ela gosta de vestidos até os joelhos e cores claras", centa a estilista Martha Medeiros.

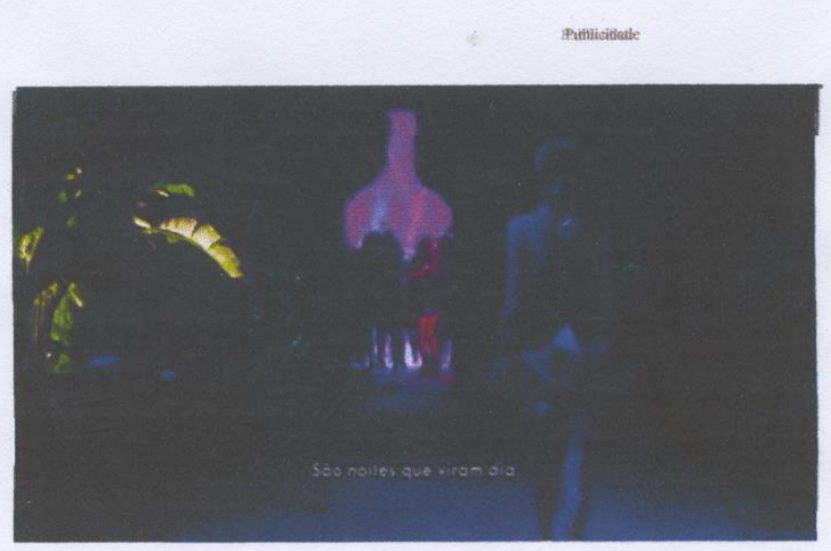

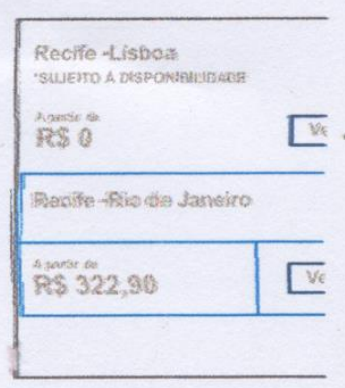

Para analisar, commpreender e forma opiniảo sobre tudo o que acontec e no mundo.

\section{Assine VE}

\section{Acesse aqui}

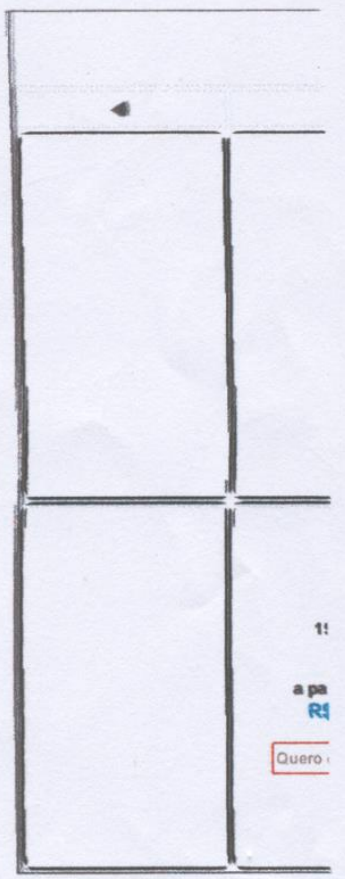

Marcela é o braço digital do vice. Está constantemente de olho nas redes sociais e mantém o marido informado sobre a temperatura ambiente. Um fica longe do outro a maior parte da semana, uma vez que Temer mora de segunda a quinta-feira no Palácio do Jaburu, em Brasília, e Marcela permanece em São Paulo, quase sempre na companhia da mãe. Sacudida, loirissima e de olhos azuis, Norma Tedeschi acompanhou a filha adolescente em seu primeiro encontro com Temer. Amigos do vice contam que, ao fim de um dia extenuante de trabalho, é comum vê-lo tomar um vinho, fumar um charuto e "mergulhar 
Bela, recatada e do lar: uma análise discursiva das posições-sujeito da mulher na revista Veja

$17 / 05 / 2016$

Marcela Temer: bela, recatada e "do lar" | Brasil | Noticias | VEJAcom

num outro mundo" - o que ocorre, por exemplo, quando telefona para Marcela ou assiste a vídeos die Michelzinho, que ela manda pelo celular. Três anos atrás, Temer lançou o livro de poemas intituladado Anônima Intimidade. Um deles, na página 135, diz: "De vermelho / Flamejante / Labaredas de fogo / Olhos brilhantes / Que sorriem / Com lábios rubros / Incêndios / Tomam conta de mim / Minha mente / Minha alma / Tudo meu / Em brasas / Meu corpo / Incendiado / Consumido / Dissolvido / Finalmente / Restam cinzas / Que espalho na cama / Para dormir".

Michel Temer é um homem de sorte.

Pela Web

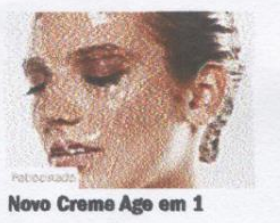

Minuto e Acaba com Rugas

e Olheiras!

(Agedess - Vock Saudavel)

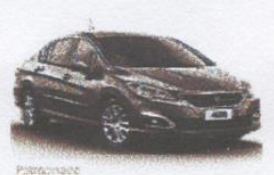

Toda linha Peugeot esta com condiçāes incriveis (Peugeot)

\section{Recomendados para você}

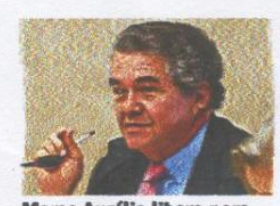

Marco Aurelio libera para julgamento ação sobre impeachment de Temer

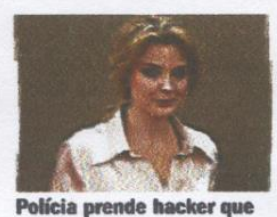

Pollicia prende hacker que

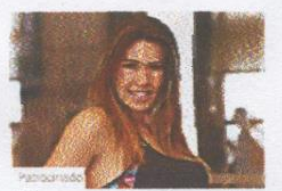

"Nunca vi algo tão rápido", disse Solanģe Frazāo sobre fórmula ploneira para... (Slimcaps - Vive Bem)

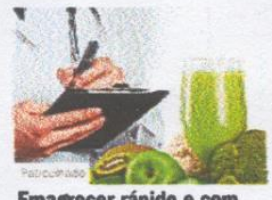

Emagrecer rápido e com

saúde: o que era sonho,

virou realidade com essa...

(Slimcaps - Medida Certa)

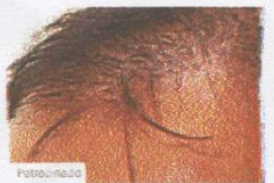

Não faça implantes antes

de conhecer o novo

tratamento que ellimina $a$.

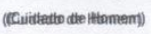

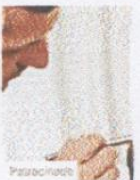

Sem efeitos et método inovad reestabelece ! (HairCaps - Clube A

Fonte: Linhares (2016). 